\title{
Loan Risk Compensation Fund Stimulating Effect on SME Loans Inspection
}

\author{
Miao Tian ${ }^{1,2,3}$ Mu Zhang ${ }^{2}$ \\ ${ }^{1}$ School of Finance, Guizhou University of Finance and Economics, Guiyang Guizhou 550025, China \\ ${ }^{2}$ Guizhou Institute for Urban Economics and Development, Guizhou University of Finance and Economics, Guiyang \\ Guizhou 550025, China \\ ${ }^{3}$ Guizhou Institution for Technology Innovation \& Entrepreneurship Investment, Guizhou University of Finance and \\ Economics, Guiyang Guizhou 550025, China
}

\section{贷款风险补偿资金对科技型中小企业贷款的拉动作用检验 \\ 田菻 ${ }^{1,2,3}$ 张目 $^{2}$

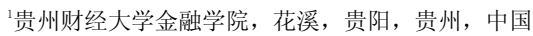 \\ 2贵州财经大学贵州城镇经济与发展研究院, 花溪, 贵阳, 贵州, 中国 \\ 3贵州财经大学贵州科技创新创业投资研究院, 花溪, 贵阳, 贵州, 中国}

\begin{abstract}
To study the stimulating effect of loan risk compensation fund for SME loans, loans play a more effective risk compensation mechanism, the paper 2015 cross-sectional data 15 provinces and is calculated using the risk-based approach to verify the compensation fund for SME analysis of the role of loans from correlation to analyze the effects of risk compensation fund for SME balance, in order to determine the effectiveness of risk compensation mechanism.

Keywords: Risk compensation funds, Linear Regression, Pulling effect
\end{abstract}

\section{摘要}

为了研究贷款风险补偿资金对科技型中小企业贷款的 拉动作用, 更加有效的发挥贷款风险补偿机制, 本文 基于 2015 年 15 个省市的截面数据采用计量的方法来 验证风险补偿资金对科技型中小企业贷款余额的作用 分析，从相关性来分析风险补偿资金对科技型中小企 业余额的影响, 以此来判断风险补偿机制的有效性。

关键词：风险补偿资金 线性回归分析 拉动作用

\section{1. 引言}

随着我国经济的发展尤其是我国科学技术的发 展, 中国的科技型中小企业越来越多。但是随之而 来面临的一个难题就是科技型中小企业融资难。在 这种情况下我国政府推出了风险补偿机制, 对放贷 银行为科技型中小企业贷款所产生的损失进行补 偿, 为科技型中小企业承担有限代偿责任。Kundid Ana (2011) 利用多元线性回归模型考察了企业的 规模和借贷成本的关系以及借贷成本的决定因素, 与大企业相比中小企业不断面临更高的借贷成本, 要求对中小企业实施更有效的支持策略和资金分 配。政府行为应该刺激信誉良好的中小企业使其更 容易获得银行融资, 并对银行面临的信用风险创造 补偿机制 ${ }^{[1]}$ 。金节、张鲁音 (2006) 以浙江省为例 进行了分析, 2005 年浙江省将工商银行和农业银行 的省分行作为试点单位, 政府对其新增小企业贷款 而产生的风险, 按贷款净额 $0.5 \%-1 \%$ 的比例给予风 险补偿 ${ }^{[2]}$ 。秦娟、费颖新、刘春辉、徐欣 (2012) 年以江苏省为例, 论述该省设立了专门用于商业银 行在支持科技型中小企业科技成果转化过程中所 发生的贷款损失的风险补偿专项资金, 江苏省对外 所放贷款承担风险的具体要求为省政府承担 $60 \%-70 \%$, 银行业金融机构承担相应的利息损失风 
Risk Analysis and Crisis Response in Big Data Era (RAC-16)

险 $^{[3]}$ 。康纪媛（2013）在分析广东省科技贷款风险 准备金问题的同时概括介绍了山东省风险补偿机 制的建立及具体措施。山东省财政厅、科技厅同人 民银行济南市分行共同研究设立了战略新兴产业 科技项目贷款风险补偿制度，对上年度科技贷款余 额同比增长 $20 \%$ 以上的商业银行, 省财政厅按照不 高于新增科技贷款余额 $1 \%$ 的比例给予风险补偿 ${ }^{[4]}$ 。 曹建强、肖德忠、任淑君、李味阳（2010）则从中 小企业和特色同业两个方面论述了当地政府对贷 款风险补偿机制进行的有效探索 ${ }^{[5]}$ 。风险补偿资金 对解决我国科技型中小企业融资难的问题所起到 的作用众说纷纭。那么风险补偿资金对科技型中小 企业融资到底起到一个多大的作用, 以及对我国以 后的类似问题具有多大的意义。目前我国的许多学 者都是从纯理论的角度来解释风险补偿资金对科 技型中小企业余额的拉动作用。本文借用计量经济 学的方法, 通过数据分析来说明风险补偿资金对科 技型中小企业贷款的拉动作用。

\section{2. 建模依据}

我们将从影响科技贷款余额的各项指标，如风险资 金补偿额度、实际 $G D P$ 、贷款余额、存款余额、银
行信用, 固定资产投资这几个方面来分析贷款风险 补偿资金对科技型中小企业贷款余额的分析, 为了 简化起见, 我们用如下的方程式来表示:

$$
S M E L_{s}=a_{0}+\beta L R C F_{s}+\psi C V^{T}+\varepsilon
$$

其中, $S M E L_{s}$ 为科技型中小企业贷款余额, $L R C F_{S}$ 为风险补偿资金, $\beta$ 为贷款风险补偿资金的边际拉 动乘数。 $c v$ 为控制变量矩阵, 控制变量包括: 实际 $G D P$ 、科技型中小企业固定资产投资总额、存款余 额、贷款余额、物价水平、经济信用化水平 (注: 本项目特指银行信用, 即银行贷款 $/ G D P$ ) 等, $\varepsilon$ 为 随机误差项。

\section{3. 数据获取}

目前科技型中小企业风险补偿机制在我国还是处 于一个发展阶段, 各个市都相应的制定了《科技型 中小企业贷款风险补偿资金池管理办法》，明确了 补偿的额度、补偿的比例等, 其次通过翻阅各个市 的《2015 年社会统计报告》, 我们得出了各个市的 $G D P$, 贷款余额等一系列影响科技型企业贷款余额 的数据。具体的数据如下表 1 :

表 1: 风险补偿资金

单位 (亿元)

\begin{tabular}{|l|l|l|l|l|l|l|l|}
\hline 地级市 & $\begin{array}{l}\text { 2015 年风 } \\
\text { 险补偿金 } \\
\text { 额 }\end{array}$ & $\begin{array}{l}\text { 2015 年增 } \\
\text { 加GDP 存款余额 } \\
\text { 增加 }\end{array}$ & $\begin{array}{l}\text { 贷款增加 } \\
\text { 额 }\end{array}$ & 银行信用 & $\begin{array}{l}\text { 固定资产投 } \\
\text { 资额度 }\end{array}$ & 科技贷款余额 \\
\hline 深圳市 & 6 & 1498.02 & 7222.55 & 4331.68 & 2.891603583 & 580.89 & 334 \\
\hline 广州市 & 5 & 1393.54 & 5224.89 & 3430.16 & 2.461472222 & 516.45 & 315.5 \\
\hline 武汉市 & 2.2 & 930.52 & 2689.32 & 2663 & 2.861840691 & 722.41 & 286.6 \\
\hline 济南市 & 1.8 & 360.68 & 1350.8 & 1189.42 & 3.297715426 & 435 & 228.6 \\
\hline 无锡市 & 1.5 & 312.95 & 751.83 & 795.49 & 2.541907653 & 266.98 & 202.08 \\
\hline 大连市 & 1 & 76 & 943.2 & 758.7 & 9.982894737 & -2214.3 & 104.46 \\
\hline 常州市 & 0.6 & 371.28 & 512.3 & 564.8 & 1.521223874 & 88.9 & 88.85 \\
\hline 温州市 & 0.5 & 317.03 & 867.27 & 493.75 & 1.557423588 & 403.58 & 64.74 \\
\hline 扬州市 & 0.5 & 382.11 & 417.38 & 363.4 & 0.951035042 & 440.16 & 58 \\
\hline 佛山市 & 0.5 & 400.64 & 456.45 & 356.9 & 0.890824681 & 423.07 & 55.7 \\
\hline 珠海市 & 0.42 & 167.66 & 489.43 & 343.74 & 2.050220685 & 170.09 & 44.5 \\
\hline 洛阳市 & 0.5 & 215.4 & 465.1 & 335.7 & 1.558495822 & 510.5 & 6.4632 \\
\hline 兰州市 & 0.2 & 169.3 & 633 & 154.87 & 0.914766686 & 193.07 & 11.18 \\
\hline 唯州市 & 0.2 & 25.19 & 97.48 & 129.46 & 5.139341008 & 99.94 & 8.9718 \\
\hline
\end{tabular}

多元统计分析是数理统计的一个分支。它研究 如何有效地整理和分析受随机影响的数据, 并对 所考察的问题作出推断或预测。多元统计分析一般 不对数据作统计模型假设, 而直接从实际出发, 考 
Risk Analysis and Crisis Response in Big Data Era (RAC-16)

察和分析大量数据的结构和特征, 从中提取主要 而准确的信息, 能帮助我们正确认识事物客观存 在的统计规律。在实际生活中, 某个现象的发生或 某种结果的得出往往与其他某个或某些因素有关, 但这种关系又难以从机理上给出准确的定量描述, 只是从数据上可以看出有 “有关的趋势” ${ }^{[6]}$ 。线 性回归分析可以用来研究具有这种特征的变量之 间的相关关系，它假设因变量与自变量之间为线 性关系, 用一定的线性回归模型来拟合因变量和 自变量的数据, 并通过确定模型参数来得到回归 方程, 然后可以通过此回归方程分析变量之间的 相关关系。本文主要使用 spss 进行相关的计量分 析。

\section{5. 分析过程}

\section{(1) 进行全回归}

我们使用 spss 软件进行全回归的分析, 经得到统计 结果如表 2 。它表明了因变量和自变量以及自变量 进入方程的情况。

由表 3 可以看出，相关系数 $R$ 为 0.989 , 说明 自变量与因变量之间有比较好的相性决定系数 $R$-Square 为 0.977 ( $R$ Square 反映出总体回归效 果, 越接近 1 越好)。

表4是使用方差分析Analysis of Variance 对
整个回归方程作显著性检验，其中 $F=57.234 ， P$ $=0.000$ 差异有显著性意义, 即此回归方程有必要 成立。

表5 是用方差分析对每个因变量做偏回归分 析。是关于回归系数及显著性检验的计算结果。说 明如下: 表中, 风险补偿资金的 $t$ 的显著性概率为 $0.02<0.05$, 表示风险补偿资金与 0 有显著性差 异，表明风险补偿资金应出现在方程中。GDP的 $t$ 的 显著性概率为 $0.923>0.05$, 表示钙含量的系数 与 0 没有显著性差异, GDP不应当作为解释变量出 现在方程中。存款增加额的 $t$ 的显著性概率为 0.004 $<0.05$, 表示存款增加额的系数与 0 有显著性差异, 存款增加额应当作为解释变量出现在方程中。贷款 增加额的 $t$ 的显著性概率 $0.009<0.05$ ，表示贷款 增加额的系数与 0 有显著性差异, 表明贷款增加 额应作为解释变量出现在方程中。银行信用的 $t$ 的 显著性概率为 $0.391>0.05$, 表示银行信用的系 数与 0 没有显著性差异, 银行信用不应当作为解 释变量出现在方程中。固定资产投资额度的 $t$ 的显 著性概率为 $0.612>0.05$, 表示固定资产投资额 度的系数与 0 没有显著性差异, 固定资产投资额 度不应当作为解释变量出现在方程中。由此可见, 风险补偿资金、存款增加额和贷款增加额可以作为

表2 进入模型的变量说明表 (Variables Entered/Removedb)

\section{输入/移去的变量 ${ }^{b, c}$}

\begin{tabular}{|l|l|l|l|}
\hline 模型 & \multicolumn{1}{|c|}{ 输入的变量 } & 移去的变量 & 方法 \\
\hline 1 & 固定资产投资额 & & 输入 \\
& 度, 银行信用, & & \\
& 存款余额增加, & & \\
& 2015年增加GDP, & & \\
& 风险补偿金额, \\
& & & \\
贷款增加额 & & \\
\hline
\end{tabular}

a. 已输入所有请求的变量

b. 因变量：科技贷款余额

c. 通过原点的线性回归

表3 模型总体参数表

模型汇总

\begin{tabular}{|c|c|c|c|c|c|c|c|c|}
\hline \multirow[b]{2}{*}{ 模型 } & \multirow[b]{2}{*}{$\mathrm{R}$} & \multirow[b]{2}{*}{$\mathrm{R}$ 方 $^{\mathrm{b}}$} & \multirow[b]{2}{*}{ 调整 R 方 } & \multirow{2}{*}{$\begin{array}{c}\text { 标准 估计的误 } \\
\text { 差 } \\
\end{array}$} & \multicolumn{4}{|c|}{ 更改统计量 } \\
\hline & & & & & R 方更改 & F 更改 & df 1 & df2 \\
\hline 1 & $.989^{a}$ & .977 & .960 & 34.490 & .977 & 57.234 & 6 & 8 \\
\hline
\end{tabular}

a. 预测变量：固定资产投资额度，银行信用，存款余额增加，2015年增加GDP，风险补偿金额，贷款增加额

b. 对于通过原点的回归 (无截距模型) , R 方可测量 (由回归解释的 ) 原点附近的因变量中的可变性比例。对于包含社 
Risk Analysis and Crisis Response in Big Data Era (RAC-16)

表 4 回归方差分析表

\begin{tabular}{|c|c|c|c|c|c|c|}
\hline \multicolumn{7}{|c|}{ Anova a, } \\
\hline 模型 & & 平方和 & $\mathrm{df}$ & 均方 & $\mathrm{F}$ & Sig. \\
\hline \multirow[t]{3}{*}{1} & 回归 & 408504.916 & 6 & 68084.153 & 57.234 & $.000^{\mathrm{a}}$ \\
\hline & 残差 & 9516.660 & 8 & 1189.583 & & \\
\hline & 总计 & $418021.577^{b}$ & 14 & & & \\
\hline
\end{tabular}

a. 预测变量：固定资产投资额度, 银行信用, 存款余额增加, 2015年增加GDP, 风 险补偿金额，贷款增加额

b. 因为通过原点的回归的常量为零, 所以对于该常量此总平方和是不正确的

c. 因变量：科技贷款余额

d. 通过原点的线性回归

\begin{tabular}{|c|c|c|c|c|c|c|c|c|}
\hline \multirow[t]{2}{*}{ 模型 } & & \multicolumn{2}{|c|}{ 非标准化系数 } & \multirow[t]{2}{*}{ 标准系数 } & $t$ & \multirow[t]{2}{*}{ sig. } & \multicolumn{2}{|c|}{$\begin{array}{l}B \text { 的 } 95.0 \% \text { 置信区 } \\
\text { 间 }\end{array}$} \\
\hline & & $\beta$ & 呩准 误差 & & & & 下限 & 上限 \\
\hline 1 & 风险补偿金额 & 88.514 & $\beta 0.528$ & 1.177 & 2.899 & 020 & 18.116 & 158.912 \\
\hline & 2015 年增加 GDP & 080 & 120 & 084 & 100 & 923 & .186 & 202 \\
\hline & 存款余额增加 & .199 & 030 & -1.770 & -4.031 & 004 & .190 & .071 \\
\hline & 贷款增加额 & 144 & 043 & 1.436 & 3.392 & 009 & 103 & 352 \\
\hline & 银行信用 & 4.284 & 4.727 & 089 & 906 & 391 & -47.544 & 8.566 \\
\hline & $\begin{array}{l}\text { 固定资产投资额 } \\
\text { 度 }\end{array}$ & 013 & 024 & 052 & 528 & 612 & .109 & 036 \\
\hline
\end{tabular}

a.因变量：科技贷款余额

解释变量存在于方程中来解释科技贷款余额的变 化，而 GDP、银行信用和固定资产投资额度应该剔 除。

（2）将 ${ }^{146} \mathrm{GDP}$ 、银行信用和固定资产投资”从自变量 当中剔除

再次运行SPSS, 得出结果。

两次统计结果的区别在于:

a . 自变量减少 “ GDP、银行信用和固定资 产投资” ;

b . R Square 值由 0.977 变为 0.954 ，可见去 掉 “ $G D P$ 、银行信用和固定资 产投资” 以后，线 性回归方程中的自变量对因变量的影响变化不大；

c. $F$ 值由原来的 57.234 上升为 $69.615 . F$ 值越 大越好, 表明整体回归效果更佳;

(3) 采用标准回归方程及其系数, 得出多元线性回
归方程

这里需要指出的是, 有常数项与无常数项是 两种不同的数学模型, 其决定系数的值不能作简 单的比较。究竟哪个回归方程更合适, 必须把它们 放到实际中检验, 才能得出正确的结论。实际工作 中, 是否保留常数项, 由经济原理来决定。这里 我们应该采用不带常数项的方程来研究, 故多元 线性回归方程为:

$$
\begin{aligned}
& z=1.177 x+1.436 y-1.77 u \\
& \text { 其中: } \\
& z \text { 表示一年科技型中小企业贷款余额的增加额, }
\end{aligned}
$$
单位为亿；

$x$ 表示一年的政府风险补偿资金，单位为亿；

$y$ 表示一年的贷款增加额，单位为亿;

$u$ 表示一年的存款增加额, 单位为亿 
Risk Analysis and Crisis Response in Big Data Era (RAC-16)

\section{6. 结论}

基于多元线性回归分析的理论和方法, 应用 统计软件 spss 对影响科技贷款余额的风险补偿资 金, $G D P$, 存款额，贷款额，固定资产投资等因素 进行统计分析。结果表明，科技贷款余额与风险补 偿资金、贷款存在正相关性，而存款含量与科技贷 款余额存在负相关性。但是我们可以发现存款余额 和贷款余额几乎可以相互抵消掉, 这也与我们的实 际情况相似，在没有风险补偿资金的情况下，科技 型中小企业融资是比较困难的, 而在政府进行了风 险补偿的情况下, 科技型企业融资贷款要容易得 多, 说明风险补偿资金对科技型中小企业贷款余额 是有拉升作用的。

\section{致谢}

本文为国家自然科学基金地区项目《贷款风险 补偿资金对科技型中小企业信贷配给的影响机理 研究》(71263011) 的阶段性成果之一。

参考文献

[1] KundidAna,ErcegovacRoberto.Compensation mechanism of the small and medium-sized enterprise credit risk.International Journal of Law \& Management. 2011, 53(1): 62-84

[2] 金节、张鲁英.我国中小企业融资问题解决方式 创新一浙江省小企业贷款风险补偿机制金融 经济.2006,2:57-58

[3] 秦娟、费渘新、刘春辉、徐欣.江苏省科技贷款 风补偿的实践与思考, 科技管理研 究.2012,4:62-64

[4] 康纪媛.广东省科技贷款风险准备金问题分析 广州华南理工大学 2013

[5] 曹建强、肖德忠、任淑君、李味阳.贷款风险 补偿制的实践与思考. 华北金融.2010.11:52-54

[6] L. Li, Z.F. Zhou, X. Lei. Evaluating of loan guarantees between parent and subsidiary based on vulnerable option. Journal of Risk Analysis and Crisis Response, 2012, 2(1):56-60. 